\title{
"Já tá chegando a festa de Nossa Senhora do Carmo": Memórias e vivências na cidade de Borda da Mata - MG
}

Cleyton Antônio da Costa ${ }^{I}$

Resumo: O presente artigo visa discutir os elementos presentes na festa religiosa de Nossa Senhora do Carmo, padroeira da cidade de Borda da Mata, Sul de Minas Gerais. Busca-se entender como os homens e mulheres deste espaço social se agenciam com o festejo religioso uma das práticas culturais e sociais mais esperadas pela comunidade. É a partir desse recorte cultural que pode-se compreender as diferentes memórias e sentidos relacionados à festa. Metodologicamente utilizamos a técnica da História Oral, que possibilitou dialogar com muitas memórias e outras histórias de diferentes gerações e significados dos festejos, bem como as permanências e rupturas desta prática cultural, que é permeada de valores, sentimentos e tensões.

Palavras-chave: Festa, Cidade, Memória.

\section{"Already coming to the feast of Our Lady of Carmo ": Memories and experiences in the city Borda da Mata-MG"}

\begin{abstract}
This article aims to discuss the elements present at the religious feast of Our Lady of Carmo, patroness of the city of Borda da Mata, south of Minas Gerais. The aim is to understand how the men and women of this social space manage with the religious festival one of the cultural and social practices most anticipated by the community. It is from this cultural cutout that one can understand the different memories and senses related to the party. Methodologically we use the technique of Oral history, which enabled dialogue with many memories and other stories of different generations and meanings of the festivities, as well as the permanence and ruptures of this cultural practice, which is permeated of values, Feelings and tensions.
\end{abstract}

Keywords: Party, City, Memory

Artigo recebido em 06/05/2017 e aprovado em 17/07/2017. 


\section{"JÁ TÁ CHEGANDO A FESTA DE NOSSA SENHORA DO CARMO": MEMÓRIAS E VIVÊNCIAS NA CIDADE DE BORDA DA MATA - MG}

\section{CLEYTON ANTÔNIO DA COSTA}

\section{Introdução}

Borda da Mata possui uma população calculada, pelo IBGE no censo de 2010, em 17.118 habitantes ${ }^{\text {II }}$, localizada no extremo sul mineiro e com sua economia baseada na agricultura e na média indústria de confecções de pijamas e tecelagens ${ }^{\mathrm{III}}$. Fazem limites com Borda da Mata, os municípios de Pouso Alegre, Congonhal, Inconfidentes e Bom Repouso.

A cidade tem seus primórdios em uma parada de tropeiros que vinham arraial de São Francisco de Paula de Ouro Fino entre o Registro do Mandu, hoje Pouso Alegre, isto em meados do século XIX ${ }^{\mathrm{IV}}$. A devoção a Nossa Senhora do Carmo fora trazida por um religioso neste mesmo período. Com o passar do tempo, Borda da Mata se torna distrito da cidade de Pouso Alegre, pela Lei Provincial no 128, de 14 de março de 1839. Em 8 de junho de 1858 é elevada a Freguesia. Tem, desta forma, um sacerdote para os exercícios dos atos religiosos, para fortalecer a devoção e manter os adeptos juntos a uma orientação eclesiástica. E em sete de setembro de 1923 foi sancionada a Lei $n^{\circ} 843$ para a criação do município e sua instalação em 16 de novembro do mesmo ano.

O festejo em louvor a Virgem do Carmelo está intrinsecamente ligado a história deste município. Assim, busca-se entender como os homens e mulheres deste espaço social se agenciam com o festejo religioso uma das práticas culturais e sociais mais esperadas pela comunidade. É a partir desse recorte cultural que poderemos compreender as diferentes memórias e sentidos relacionados à festa.

Neste olhar deparamos com as considerações de Abreu ao mostrar que

o historiador, no meu modo de ver, encontra dois grandes desafios: pensar os significados e mudanças das festas em sua própria historicidade, mas sobretudo, compreender a dinâmica relação das festas com a experiência dos homens e mulheres que as tornaram, em qualquer época e local, autêntica e concorrida ${ }^{\mathrm{V}}$.

Compreendemos que a festa não se define apenas como uma aglomeração de pessoas em um determinado horário e espaço, pois é também, por meio das festas, que nos é possibilitado evidenciar múltiplos elementos que indiquem religiosidade, lazer, economia, política, tensões, conflitos, entre outros, proporcionando uma gama de reflexões que atravessam o festejar vivenciado por diferentes sujeitos sociais.

\section{Festejar a padroeira e os seus diferentes significados.}

Estabelecer um padroeiro para um povoado configura-se uma referência religiosa, que tange à proteção divina. E, também, a celebração do dia deste santo, como aqui 16 de julho, proporciona um dia permeado por diferentes significados e práticas.

A festa constitui um dos momentos mais importantes para o município, reunindo um grande número de homens, mulheres e crianças e, da mesma forma, os "filhos da terra" que moram em outras localidades retornam à cidade natal para reencontrar parentes e amigos. Os dias da festa são marcados pela fé, lazer e sociabilidade. 


\section{"JÁ TÁ CHEGANDO A FESTA DE NOSSA SENHORA DO CARMO": MEMÓRIAS E VIVÊNCIAS NA CIDADE DE BORDA DA MATA - MG}

\section{CLEYTON ANTÔNIO DA COSTA}

Em Borda da Mata, 16 de julho se reafirma com um dia festivo, em que se celebra a padroeira, Nossa Senhora do Carmo, com o festejo organizado pela Igreja Católica. Ao longo dos anos foram se incorporando outros elementos, à comemoração da cidade no dia da padroeira, moldando uma data repleta de significados e sentidos, denominada como "Festa da Borda"

Aqui será apontada a (re)significação dada à festa ao longo dos tempos, nisto é pertinente pensar sua agenda, programação e atores que integram sua realização.

A festa, na sua parte religiosa, é constituída por diferentes práticas, que são a novena, a imposição do escapulário, a procissão, a coroação da imagem da padroeira e a quermesse, organizadas pelo padre e leigos que frequentam a paróquia Nossa Senhora do Carmo.

A divulgação do festejo ocorre através de cartazes, que contem informações referentes à festa como o cronograma e programação das atividades.

Trazemos o cartaz da festa religiosa referente ao ano de 2011.

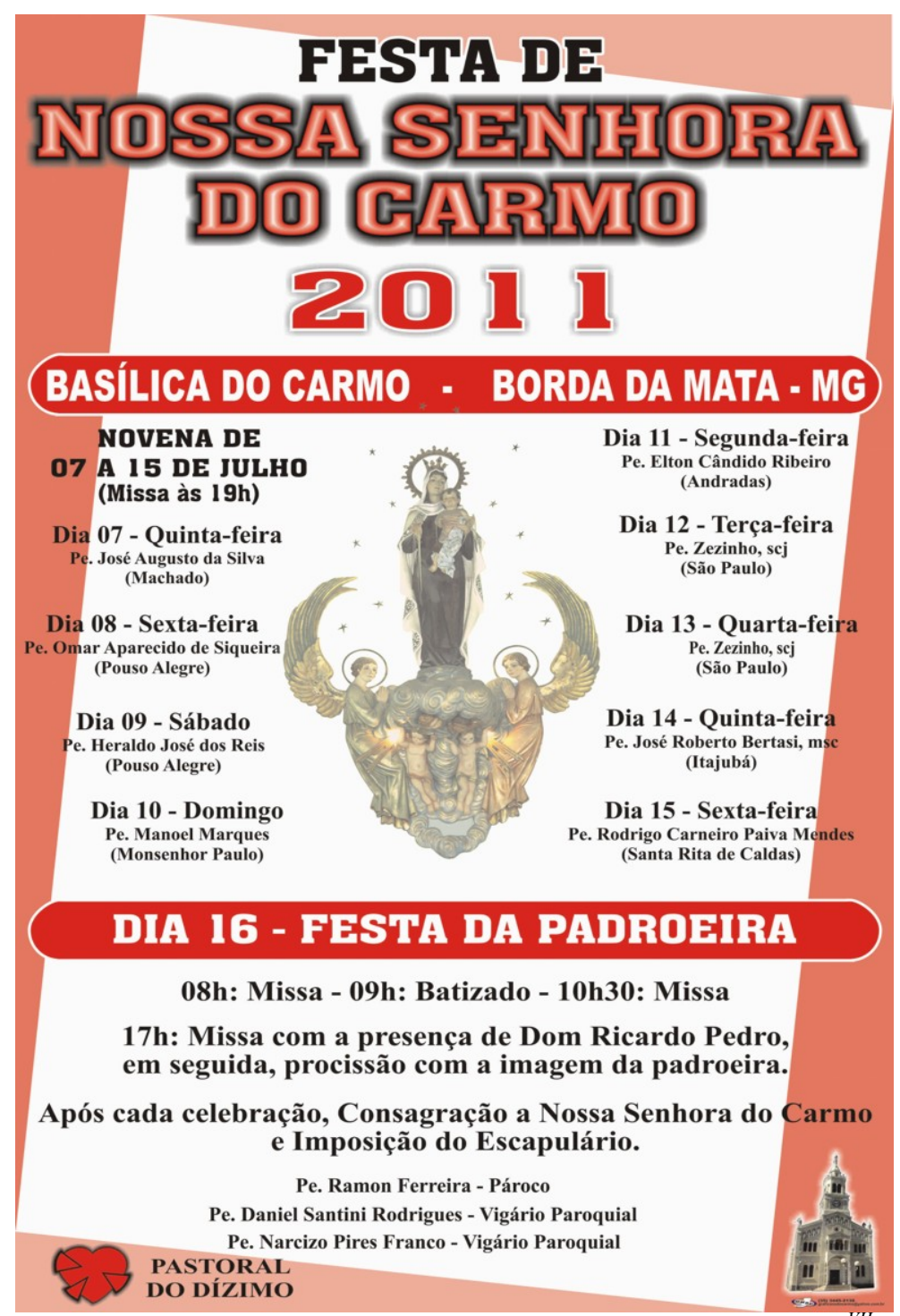

Imagem 1 - Cartaz da festa de Nossa Senhora do Carmo de $2011^{V I I}$.

Cadernos do Tempo Presente, São Cristóvão-SE, v. 08, n. 04, p. 93-105, jul./dez. 2017| http://www.seer.ufs.br/index.php/tempo 


\section{“JÁ TÁ CHEGANDO A FESTA DE NOSSA SENHORA DO CARMO": MEMÓRIAS E VIVÊNCIAS NA CIDADE DE BORDA DA MATA - MG}

\section{CLEYTON ANTÔNIO DA COSTA}

E o cartaz da programação da paróquia centraliza a imagem de Nossa Senhora do Carmo, prescrevendo que a festa é em seu louvor e que todas as atividades desenvolvidas norteiam o "DIA 16 - FESTA DA PADROEIRA".

Ao preparar 16 de julho, dedicado à santa padroeira, ocorre a novena nos nove dias consecutivos antecedentes ao dia da festa com a realização de missas e orações específicas.

Dona Lola Rodrigues ao relembrar as festas, quando era criança e adolescente menciona uma prática que demonstra a implicação de um momento diferente na vida dos bordamatenses.

\footnotetext{
O que era bonito durante a festa, o dia que começava a novena, quatro horas da manhã tinha alvorada com a banda de música e fogos. É muito bonito, sabe? E o dia da festa, mesmo, dia dezesseis, quatro horas da manhã, alvorada e fogos, bastante fogos mesmo. Era muito bonito. E eles soltavam fogos todos os dias de novena, agora pararam, né? ${ }^{\mathrm{VIII}}$
}

Um tempo distinto é estabelecido, marcado pelo júbilo e devoção, e que se inaugura com a alvorada ao raiar do primeiro dia dos festejos. Essa é uma prática recorrente nas festas religiosas. Os dias da novena projetam a proximidade do dia da padroeira, que configura a mudança da forma de ver e sentir a festa. Isto é devido, à presença da alvorada, quando fogos de artifícios e músicas intensificam a preparação para a festa.

A narradora aponta que não é em qualquer data que ocorre a alvorada, mas sim no "dia que começava a novena". Culminam-se dias de alegrias, da concretização de tanta espera ao longo do ano. A descrição como "muito bonito" impõe à alvorada uma dimensão de rompimento do cotidiano, despertando a população para mais uma festa. Ou seja, traz a confirmação de um momento especial cercado de fé, alegria e encontro. dias atuais.

Conforme é apresentado, esta prática, que a tantos encantou, não é realizada nos

É pertinente ressaltar que não se pode ver a festa como algo estagnado, mas sim em um processo ativo de constituição, em que elementos ou práticas podem ou não ser incluídos em sua realização.

A novena organizada pelo sacerdote possui objetivos específicos como se vê na matéria divulgada no Jornal Tribuna Popular: "A novena de Nossa Senhora do Carmo, que foi de 7 a 15 de Julho, fez um aprofundamento sobre o Espírito Santo com o objetivo de fortalecer a fé dos cristãos e estimulá-los a participar da comunidade eclesial e da nova evangelização". IX

Juntamente com as missas realizadas ao longo dos nove dias seguidos, há o costume de convidar sacerdotes de outras paróquias para celebrarem a missa. A cada missa é refletido um tema que esteja vinculado à temática central, como vemos no fragmento acima em 1998, em que a reflexão foi sobre o Espírito Santo.

Aqui emerge a preocupação da Igreja Católica com os seus fiéis, ou seja, o tempo festivo não se resume ao festejar por si só, mas direciona os participantes da celebração a terem outro olhar e postura. 


\title{
“JÁ TÁ CHEGANDO A FESTA DE NOSSA SENHORA DO CARMO": MEMÓRIAS E VIVÊNCIAS NA CIDADE DE BORDA DA MATA - MG
}

\section{CLEYTON ANTÔNIO DA COSTA}

A novena assume um caráter pedagógico, conduzindo o fiel a adquirir conhecimentos da doutrina cristã pregada pelo catolicismo e propiciar a vivência em comunidade.

Assim, deparamos com a questão de comunidade, que não é vista como uma união homogênea e uniforme. Padre Luís Carlos Osti explica a relação que há entre a paróquia e as comunidades.

\begin{abstract}
A paróquia é organizada como rede de comunidades, cada setor, cada setor tem uma igreja, capela que leva o nome de um santo padroeiro que a própria comunidade define. E nós somos ao todo, em todo o município de Borda da Mata, somos trinta comunidades [...], são doze urbanas e dezoito rurais. Todas elas tem seus líderes, tem suas equipes financeiras, seus conselhos financeiros e eles estão todos formados e existe uma conexão com a igreja mãe, que é a basílica de Nossa Senhora do Carmo e é por isso que falamos rede de comunidades, são formados como uma rede, que se interligam, todos se interligam e tem como mãe, a basílica de Nossa Senhora do Carmo. ${ }^{\mathrm{X}}$
\end{abstract}

A fala do sacerdote apresenta o panorama da paróquia, que é a porção de um território, formado por diversas comunidades, cada qual possuindo sua dinâmica e vivência. A paróquia, na celebração de sua padroeira, reúne todas as suas comunidades, formando uma concentração pautada na vivência religiosa. Nessa concentração é materializado este ponto de união, que é devoção à padroeira.

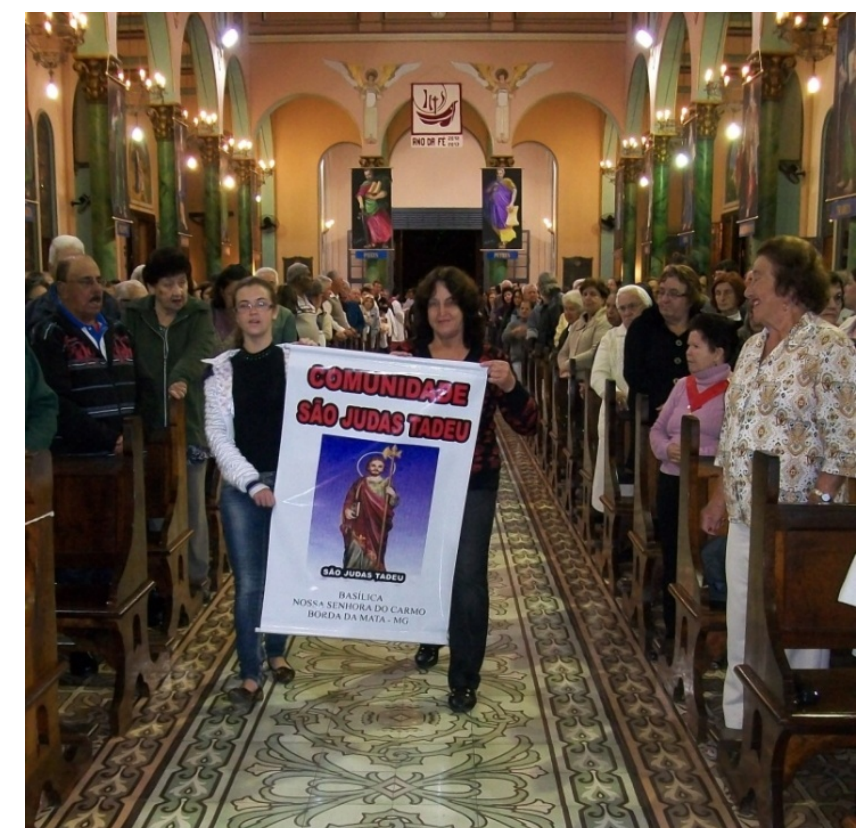

Imagem 2 - Comunidades da paróquia que participam do momento celebrativo na Igreja Matriz ${ }^{X I}$

Notamos na fotografia o evidenciamento das comunidades que formam a paróquia, no caso aqui, a Comunidade São Judas Tadeu. A igreja lotada para a celebração eucarística demonstra a reunião que é proporcionada pela preparação da festa religiosa. A igreja matriz é o cenário para a festa em louvor à Nossa Senhora do Carmo, possibilitando uma convivência pautada no estar junto com familiares, amigos,

Cadernos do Tempo Presente, São Cristóvão-SE, v. 08, n. 04, p. 93-105, jul./dez. 2017| http://www.seer.ufs.br/index.php/tempo 


\section{“JÁ TÁ CHEGANDO A FESTA DE NOSSA SENHORA DO CARMO": MEMÓRIAS E VIVÊNCIAS NA CIDADE DE BORDA DA MATA - MG}

\section{CLEYTON ANTÔNIO DA COSTA}

turistas em um espaço dedicado aos ritos fixos da missa. Conforme aponta Lucena "o festejo funciona como mecanismo de neutralização dos conflitos e diferenças, cria uma convivência ilusória de que a sociedade é igualitária e solidária"XII . Como a igreja é um espaço constituído pela fraternidade, a formação da assembleia, a festa nesse território neutraliza os conflitos, teoricamente, pelo fato de que todos que ali estão em busca de contrição, bênçãos.

Diante deste panorama apontamos o olhar eclesiástico para a festa de Nossa Senhora do Carmo. Na Folha Paroquial em seu número 06, do mês de Junho de 1999, Padre Edson Oriolo (foi pároco em Borda do ano de 1997 a 2007) redigiu o artigo "Festa da Padroeira", e com destaque de primeira página descreveu:

\footnotetext{
as festas têm enorme sentido em nossa vida. Elas amenizam os sofrimentos. Têm o Dom de conservar em nós a alegria e nos dão coragem de prosseguirmos nas lutas do dia-a-dia. Marcam etapas, nos proporcionam oportunidades de novas amizades, reencontros ... enfim, são bálsamos agradáveis e estimulantes. ${ }^{\text {XIII }}$
}

Como instrumento de divulgação das atividades paroquiais, o Jornal Folha Paroquial traz a programação da Festa de Nossa Senhora do Carmo do ano de 1999 e com o intuito de mobilizar informando o artigo do sacerdote que tem um tom mais antropológico ao apresentar a festa como momento privilegiado para repor as energias, de revigorar-se espiritualmente e afetivamente, etc.

"A festa é uma celebração do elo; 'renova os pactos, rejuvenesce as uniões', precisamente, é o próprio ela em ação. É o tempo/espaço de múltiplas trocas de rivalidades, de prestígios. É exuberância de vida e vigor fecundante, e reforça a comunhão"XIV .

Ao celebrar este momento com a comunidade responsável, o sacerdote promove a reafirmação do elo, em que ele se configura como o porta-voz dos códigos normativos para a vivência do cristão. E neste revigorar festivo a devoção a Nossa Senhora do Carmo é o ponto estratégico, pois, assume o papel de progenitora espiritual e promove a renovação do acreditar nas virtudes de Maria, como exemplo para os católicos.

A preparação das festas com as possibilidades que "marcam etapas' se funde com certa sintonia com a narrativa de Maria Ângela ao compartilhar:

\footnotetext{
A festa de Nossa Senhora do Carmo era... aqui em Borda, o esperado era o Natal e festa de Nossa Senhora do Carmo. De todas as datas, a gente marcava no calendário pela festa de Nossa Senhora do Carmo e pelo Natal. Quando a gente tava trabalhando: 'Nossa! Já tá chegando à festa de Nossa Senhora do Carmo, férias! $\mathrm{XV}$
}

Aqui vemos quão significativa é a festa de Nossa Senhora do Carmo para a senhora Maria Ângela, comparando a com as festas natalinas. Pode-se entender esta fusão pelo fato de que esses dois momentos favoreçam a reunião familiar, por serem períodos de férias, de descanso. E, também, fica evidenciada a expectativa pela chegada de festa. 


\title{
“JÁ TÁ CHEGANDO A FESTA DE NOSSA SENHORA DO CARMO": MEMÓRIAS E VIVÊNCIAS NA CIDADE DE BORDA DA MATA - MG
}

\section{CLEYTON ANTÔNIO DA COSTA}

Como afirma Burke, "as pessoas contavam o tempo pelas grandes festas"XVI . A realização das festas estrutura-se em um tempo/espaço. Elabora-se um espaço extraordinário constituído por outras dinâmicas e um tempo estabelecido, formulando desta maneira a espera pela chegada e vivência do evento. Portanto, compreendemos que "as representações do mundo social assim construídas, embora aspirem à universalidade de um diagnóstico fundado na razão, são sempre determinadas pelos interesses de grupo que as forjam"XVII. A busca em fixar a festa como uma data de espera constrói uma expectativa, e esta se dinamiza de maneira certa, estar com a família, recesso escolar, materializar a devoção, entre outros. Forja-se um momento aguardado, ao registrar no calendário tal evento que institui um acontecimento cujo culminar traz sentimentos, valores durante o cotidiano regido pelo trabalho $\mathrm{e}$ obrigações.

Outro ponto dentro da celebração das missas é a imposição do escapulário, que segundo Carlos Rafael se reveste em um símbolo de proteção:

\begin{abstract}
O escapulário, ele é, analisando o que a gente usa hoje, uma medalha, um cordão com duas imagens. A imagem de Nossa Senhora do Carmo e a imagem de Jesus, né? Que você usa no pescoço que toda uma... tem todo um contexto, fazer a imposição, né? É uma celebração que o padre benze o escapulário, você tem que usar, tem gente que diz que tem que ganhar. Há todo esse contexto, mas, ele pro devoto de Nossa Senhora do Carmo tem esta questão, do cuidado, tem outro contexto... tem uma questão como se fosse uma promessa de Maria, de quem usa o escapulário vai acontecer uma graça, não sei agora como é. Não me lembro exatamente. A história do escapulário, que ela recebeu, não lembro, quem recebeu no Monte Carmelo. Não me lembro detalhe, quem entrega, quem recebeu, isto não lembro. Embora que seja bastante falado na semana da festividade e é comum na nossa cidade o pessoal usar. ${ }^{\text {XVIII }}$
\end{abstract}

Carlos Rafael menciona o ritual de imposição (benção) do escapulário, ele cuja história e origem não se recorda, mas guarda o sentimento positivo e respeito.

A Igreja posiciona-se como mentora desta prática religiosa, configurando um olhar atrelado à proteção, à salvação, à seleção daqueles que usam o escapulário em relação àqueles que não portam o símbolo.

O narrador enfatiza que embora "seja bastante falado na semana da festividade" não se recorda do histórico do escapulário. A concentração na divulgação do uso do escapulário com seus benefícios espirituais traz em si a busca pelo conforto ditado pela "promessa de Maria".

Porém, o uso rompe os limites ditados pela Igreja, ao apontar que "tem gente que diz que tem que ganhar" o escapulário para desta forma usá-lo. Isto indica que a prática religiosa comporta ou possibilita explicações outras que não aquelas liberadas pela hierarquia da Igreja, oficiais, portanto.

Dentro do dia da festa, 16 de julho, o ritual de imposição é apresentado como um sinal de esperança.

Com o final da missa, a procissão na qual os fieis saem em cortejo dos fiéis junto à imagem da padroeira, colocada em andor ornamentado com flores. Esta prática, 


\title{
“JÁ TÁ CHEGANDO A FESTA DE NOSSA SENHORA DO CARMO": MEMÓRIAS E VIVÊNCIAS NA CIDADE DE BORDA DA MATA - MG
}

\section{CLEYTON ANTÔNIO DA COSTA}

durante alguns anos, ocorria antes da missa solene, atualmente é realizada após a celebração eucarística, que é presidida por bispos.

A procissão é uma atividade que remete ao Brasil colonial, conforme descreve Del Priore em seus estudos sobre as festas.

\begin{abstract}
A difusão das procissões, em dias de festa religiosa, colocava em evidência a mentalidade das populações, que viam no rito processional uma função tranqüilizante e protetora. Itinerários para a comunidade, cantos e litanias somavam-se, ora para coroar as procissões ordinárias (acompanhamento de grandes cerimônias, desfiles, datas da agenda real, canonizações), ora para atender necessidades constrangedoras (saúde do rei, falta de chuvas,

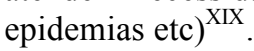

Mesmo que seu foco priorize outras temporalidades, a historiadora expõe fundamentos teóricos que contribuem na análise desta prática presente no dia 16 de julho em Borda da Mata. Tem-se aqui a constituição de uma atividade que possui funções específicas dentro da festa.

Primeiramente, é uma ação que sai dos limites físicos do templo e vai para as ruas, ou seja, a devoção circula pela cidade. A experiência de fé percorre o espaço urbano expondo a devoção mariana publicamente.

Padre Luís Carlos Osti, vigário paroquial de Borda da Mata, descreve a procissão como um elemento de tanta importância para a Igreja e a para as memórias dos participantes.

Então, a procissão tem aquele sentido do caminhar, de igreja peregrina, de igreja que caminha. Nós como católicos, nos temos uma visão de quem somos aqui na terra, peregrinos, caminhantes e sempre em nossa frente temos é... estandartes, como qualquer da tradição portuguesa, da tradição, porque vem isto, peregrinos temos alguém que vai a nossa frente. E costuma nestas procissões levar a padroeira, que representa esta força que coloca pra frente, aqui no nosso caso é a imagem de Nossa Senhora do Carmo, então as procissões, e como sempre, é uma coisa de devoção. A procissão de Nossa Senhora do Carmo foi crescendo no coração, desde criança, porque desde pequeno para mãe, são duas grandes procissões que o povo não perde, a procissão de seu padroeiro e a procissão do senhor morto, que carrega muito gente, porque são tradições que vem da infância. Então, a mulher grávida para ter o filho com saúde, para ter um bom parto, faz a promessa de caminhar na procissão, depois a criança nasce, daí acompanha a procissão de anjinho, depois acompanha, vai crescendo, depois mesmo que tá jovem, adolescente, ele acompanha, então é uma coisa que está dentro do coração de todo mundo. Praticamente, aqui em Borda da Mata, então a procissão tem esta conotação psicológica de as pessoas carregarem desde pequeno está ou tem que participar da procissão, pode nem fazer o novena, nem vim na novena. Mas, a procissão de Nossa Senhora do Carmo é como se fosse um ato de agradecer a Deus, de fortalecer-se, de olhar para frente estamos caminhando e com Nossa Senhora, com Maria, a imagem de Maria pode ver que ela ta no meio do povo, nunca ta a frente, né? Ela tá junto com o povo, ela ta caminhando. Eles fazem uma imagem pesada, é uma imagem que precisa de muitas pessoas para carregar, faz de uma forma ou outra segura para todo mundo carregar o andor. As mulheres, as famílias ajudam com a

\footnotetext{
http://www.seer.ufs.br/index.php/tempo
}

Cristóvão-SE, v. 08, n. 04, p. 93-105, jul./dez. 2017| 


\section{“JÁ TÁ CHEGANDO A FESTA DE NOSSA SENHORA DO CARMO": MEMÓRIAS E VIVÊNCIAS NA CIDADE DE BORDA DA MATA - MG}

\section{CLEYTON ANTÔNIO DA COSTA}

flores, então vai, é uma coisa muito bonita que mexe com a história, com a infância, com o coração, que mexe com tradições antigas e o povo mantém até hoje. ${ }^{\mathrm{XX}}$

Padre Luís Carlos Osti apresenta um panorama acerca da procissão dentro do festejo em Borda da Mata.

A principal ideia dita pelo padre é que a procissão simboliza para os cristãos, o caráter provisório e passageiro da vida na terra, na qual todos são apenas peregrinos. Esta é uma leitura realizada a partir da ótica eclesiástica.

Saindo da visão estritamente eclesiástica, sair às ruas em procissão pode significar que os devotos levam as rezas e cânticos religiosos para o seu próprio campo, isto é, a rua, podendo vivenciá-la com mais autonomia. Existem várias situações nas quais os devotos dos santos, pessoas que se consideram tementes a Deus, organizam procissões, sem a participação de padres, movidos por suas próprias necessidades e por iniciativa própria: procissões de Nossa Senhora, procissões para poder o fim dos períodos de seca, chamadas de penitências.

Assim, depara-se com a realização de práticas dentro da festa que configuram como um conjunto de experiências, que passam pela vida dos participantes, incorporando novos significados. Esses significados às vezes se traduzem em pedidos de graças, de saúde, proteção e/ou agradecimento àquilo que foi solicitado à santa padroeira.

Visualizar os diferentes momentos da festa possibilita conhecer práticas e valores que permeiam este período em Borda da Mata. A fotografia não é uma simples ilustração, mas uma fonte que permite evidenciar várias questões pertinentes ao objeto de estudo. Deve-se olhar para a fotografia de modo crítico, pois

\footnotetext{
ela associa vários níveis concomitantemente: aquele do sujeito tornado objeto ou que, conscientemente, se dá a fotografar, o do fotógrafo que traduz ou tentar traduzir as imagens que ele identifica, o contexto no qual a fotografia é tomada, enfim, o ou os receptores que, por sua vez, percebem imagens. Estamos lidando como uma verdadeira mensagem codificada, na qual é preciso penetrar na pluralidade dos níveis de significação"XXI .
}

Com a junção de intencionalidades presentes na fotografia, deparamos com as seguintes imagens que nos conduzem a olhar a procissão de outras maneiras. 


\section{"JÁ TÁ CHEGANDO A FESTA DE NOSSA SENHORA DO CARMO": MEMÓRIAS E \\ VIVÊNCIAS NA CIDADE DE BORDA DA MATA - MG}

\section{CLEYTON ANTÔNIO DA COSTA}

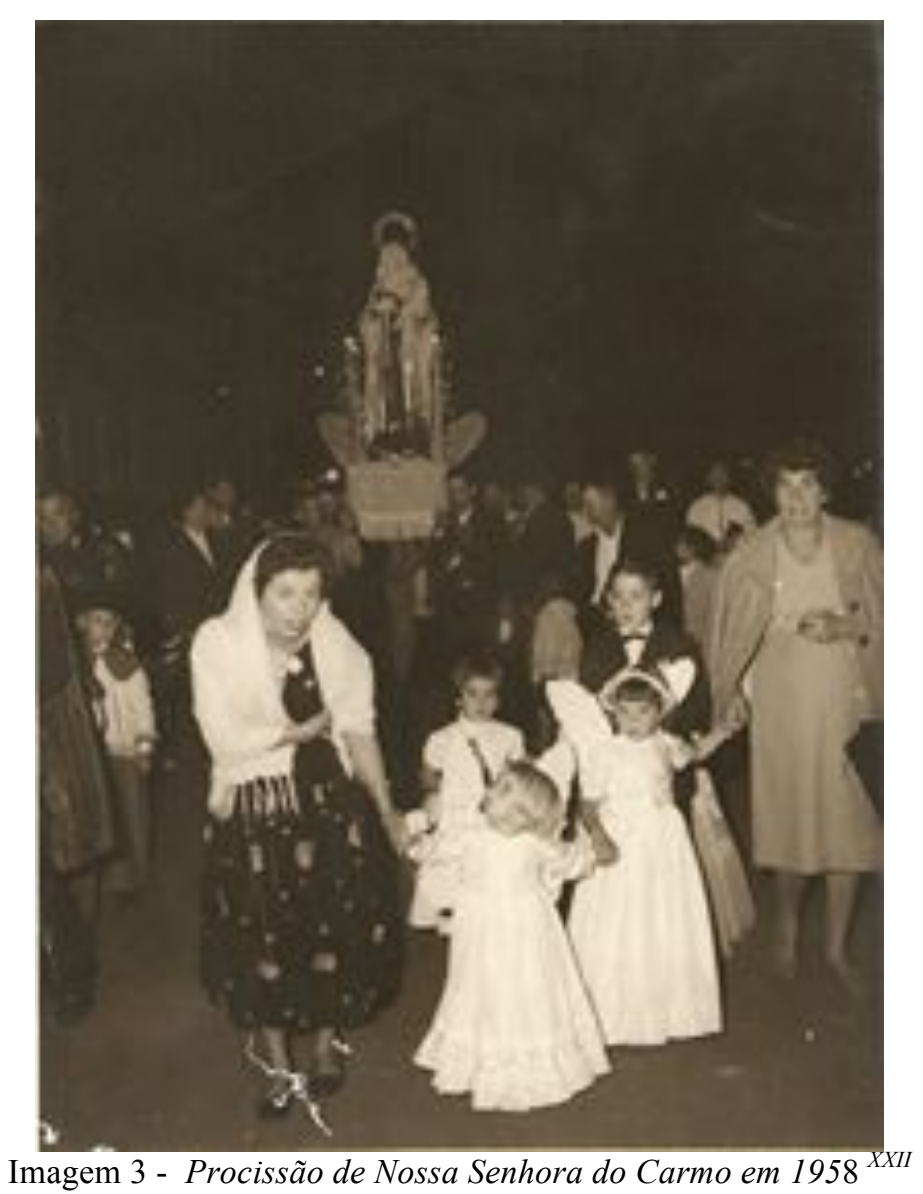

Em primeiro plano estão focalizadas as crianças, acompanhadas por suas mães, vestidas de branco que integram o espaço festivo. A transmissão dos valores, que estão ligados à religiosidade, se faz presente neste momento em que a devoção à padroeira é tida como centro.

O posicionamento das crianças dentro da procissão: abrem o cortejo religioso, indo à frente da imagem da santa. Mesmo sem a ciência efetiva do que significa do ponto de vista religioso o ato de que se participa, percebem que é um dia diferente, na qual ocupam um lugar de destaque. É claro que cada criança pode elaborar em sua mente e em seus sentimentos, outros significados bem diferentes daqueles propostos pelos adultos. As crianças podem ter suas próprias percepções da festa e da procissão, não se enquadrando nas definições oferecidas pela hierarquia da Igreja nem mesmo pelos adultos que lhe são próximos.

Ao longo do tempo, as práticas culturais não se mantêm da mesma forma, alteram-se conforme interesses e negociações. Abaixo vemos outra maneira de vivenciar a procissão. 


\section{"JÁ TÁ CHEGANDO A FESTA DE NOSSA SENHORA DO CARMO": MEMÓRIAS E VIVÊNCIAS NA CIDADE DE BORDA DA MATA - MG}

\section{CLEYTON ANTÔNIO DA COSTA}

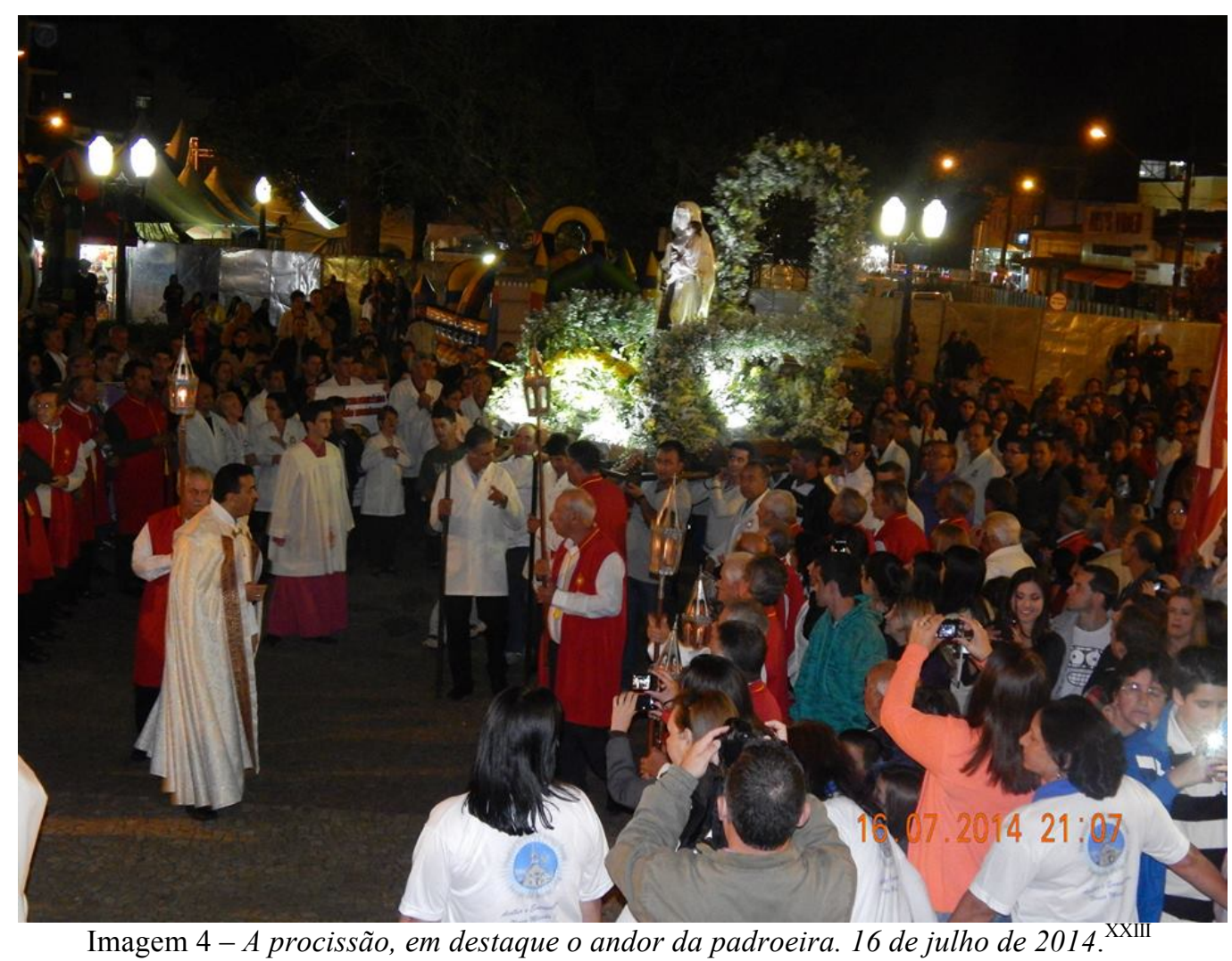

A imagem da padroeira é o ponto de referência, grande parte dos participantes se direciona a ela para poderem visualizá-la. Alguns fotografam este momento com o intuito de terem uma lembrança desta parte da festa. Alguns homens conduzem o andor que sustenta a santa. $\mathrm{O}$ andor ornamentado por flores sobressai no cortejo festivo, estando acima das pessoas.

A participação na festa possibilita a construção de memórias, em que a vivência do festejo entrelaça com as experiências vividas e compartilhadas junto aos significados atribuídos nos diversos momentos que aguçam os sentimentos, os valores e interesses.

Realizada a procissão, chega o momento de encerrar as práticas religiosas com a coroação da imagem da padroeira.

É organizada uma encenação, cujo destaque se constitui no ato de colocar uma coroa sobre a cabeça da imagem da padroeira que esteve na procissão, simbolizando o reconhecimento de sua divindade e de seu reinado.

No ano de 1958, o concurso da "Rainha do Centenário" organizado por Monsenhor Pedro Cintra, visava angariar fundos para as obras de acabamento da igreja matriz. Austerlina Cobra foi a vencedora por ter levantado o maior valor em dinheiro e com isto foi a coroante deste ano. E expõe seu olhar a este momento em sua vida:

... tem um significado maior, é uma maravilha para você, tá ali coroando a sua mãe santíssima. Pensar que ela foi coroada pelos anjos na presença de Jesus e Maria. Agora a gente pensa que a gente ta significando os anjos, né? Na presença de Deus. E muito... muito significante ${ }^{\text {XXIV }}$.

Cadernos do Tempo Presente, São Cristóvão-SE, v. 08, n. 04, p. 93-105, jul./dez. 2017| http://www.seer.ufs.br/index.php/tempo 


\title{
“JÁ TÁ CHEGANDO A FESTA DE NOSSA SENHORA DO CARMO": MEMÓRIAS E VIVÊNCIAS NA CIDADE DE BORDA DA MATA - MG
}

\section{CLEYTON ANTÔNIO DA COSTA}

Sua fala é atrelada aos ensinamentos religiosos, onde a figura de Maria refere-se à mãe, por ser considerada a mãe de Jesus Cristo. Participar deste ato condensa num "significado maior", pelo fato de uma pessoa ser escolhida ou eleita para realizar a coroação e, conforme Austerlina afirma "é uma maravilha para você". A coroante coloca-se em evidência diante de toda a população, atribuindo um olhar diferenciado para essa participação na festa.

Dona Lola Rodrigues foi festeira em 1984, juntamente com o seu esposo e relata como foi a organização da coroação que esteve sob sua responsabilidade.

\begin{abstract}
Chegou na hora da coroação, teve que fazer um palco muito bonito lá fora, na porta da igreja, né? E a gente cobriu co tecidos em volta, tudo muito bonito mesmo, né? Levou duas meninas das duas festeiras que ia coroar Nossa Senhora, ai mais quatro crianças, um para levar a palma e a coroa e mais dois anjos. Ai peguei, vesti os anjos de azul, as coroantes de azul, dois anjos de branco e dois de azul, sabe? E ai na hora da coroação, eu pedi emprestado as cornetas pros festeiros, pros da banda de música, sabe? Eles emprestaram, então, ela não tocou neste momentinho, ela não tocou. E ai ela tocou lá na torre da igreja. Eles apagaram a luz quase de tudo. Aí representou que os dois anjos estavam tocando o silêncio, sabe? Foi muito emocionante, sabe? Quanta gente, sabe, a gente que tava, ali, onde é o coreto, era o leilão, sabe? Tava lá no coreto, sabe? E choraram de emoção de ver... para a festa para este momento, sabe? Ai tocou aquele silencio muito bonito, foi a pena que naquela época não tinha filmagem ainda, sabe? Aí corou Nossa senhora tudo, aí foi a queima de fogos, que era em volta da igreja. Teve uma queima de fogos muito bonito demais ${ }^{\mathrm{XXV}}$.
\end{abstract}

A narradora descreve sua experiência na organização deste ato público, o mais aguardado dentro da festa e envolto de solenidades, como uma das suas obrigações de festeira.

Há uma distribuição nas funções do processo de organização da festa, pois, vê-se que "a memória é sempre algo construído, no presente, em função das experiências da pessoa que fala. Essa pessoa vai, inclusive, esquecer-se de muitas coisas e, talvez, no momento em que ela estiver falando, vai construir a maneira pela qual ela percebe seu passado, o passado de seus pais e de seus avós"XXVI

Compartilhar memória traduz-se em um ato político. Muitas vezes, a emoção toma conta e vêm as lágrimas, olhos marejados se fazem presentes. Mas, disponibilizar as recordações individuais e socialmente vividas percorre um caminho trilhado: "O que eu devo falar?", “O que vou falar?”. A construção da narrativa se faz um momento que articula evidenciar o que possui significados e valores e deixar de narrar instantes ou fatos que não trazem um sabor doce ao contexto apontado.

Ao perceber sua relação como festeira, que trabalhou, dedicou, juntamente com seu esposo, filhos, famílias de outros festeiros, amigos e pessoas envolvidas na igreja, buscou tomar como referência ocasiões que trazem sensações de um trabalho realizado e aceito pela população.

A narradora se lembra de que a coroação de Nossa Senhora no ano de 1984 foi realizada "lá fora, na porta da igreja". 


\title{
“JÁ TÁ CHEGANDO A FESTA DE NOSSA SENHORA DO CARMO": MEMÓRIAS E VIVÊNCIAS NA CIDADE DE BORDA DA MATA - MG
}

\section{CLEYTON ANTÔNIO DA COSTA}

Lola Rodrigues aponta a solenização com que é feito o ato de coroar a imagem. Roupas específicas, local de destaque, música que sugere uma tomada de postura, de respeito.

Olhos e ouvidos voltados para este momento de devoção. Conforme afirma a narradora "para a festa, para este momento". Institui-se uma encenação norteada na homenagem a Maria, que representa a mãe dos católicos. Com o ato de coroar a imagem da padroeira é propagada, desta forma, a devoção e reverência vivenciadas pela Igreja diante da devoção mariana.

Em alguns anos eram os filhos dos festeiros que integravam este cenário, mas com o passar do tempo iniciou-se a participação das escolas do município de Borda da Mata.

Diante desta possibilidade de visibilidade frente à população bordamatenses é atribuído a este momento uma honraria, como vemos no fragmento da matéria do Jornal Tribuna Popular de 30 de julho de 2002 que foi intitulada "Coroação de Nossa Senhora do Carmo" redigida por Ernestina Teodoro Costa Monteiro.

\begin{abstract}
Entre todas as comemorações de nossa cidade, o ponto máximo é a festa de Nossa Senhora do Carmo. Foi com grande satisfação e orgulho que a Secretária de Educação recebeu o convite do nosso pároco Edson, para coroar Nossa Mãe e Rainha. Foram nove dias de novena onde os fieis renderam homenagens a Nossa Senhora. A fé dos bordamatenses mais uma vez foi comprovada pelo número de fieis que lotavam a Matriz, participando fervorosamente das liturgias, aclamando nosso amor filial. Para encerrar esta jornada de fé cristã foi realizada no dia 16 de julho, a coroação de Nossa Rainha pelas Escolas Municipais. A emoção tomou conta de toda a população que participava do encerramento da festa. Os professores, serventes e motoristas acompanhados por Polly e Nazareth cantaram com alegria e júbilo por estarem homenageando Nossa Mãe. Está de parabéns nossa Secretária, Gláucia Brandão Guilherme que não mediu esforços para a apoteose da festa ${ }^{\mathrm{XXVII}}$.
\end{abstract}

As escolas municipais são representadas por seus alunos no ato da coroação. Encerrar a festa, que é a principal da cidade, exige trabalho como foi citado no texto. A incumbência dada à secretária de educação, Gláucia Brandão, configura-se em expressar organização e respeito pelo fato de ser uma ação que remete a homenagear a padroeira da cidade.

Dona Maria Ângela descreve este momento como "a apoteose da festa, da festa religiosa, que acabava a coroação e começa a bagunça lá na rua, né?"XXVIII . A definição como apoteose corresponde à visualização de uma situação carregada de significados. É a concretização da parte religiosa, onde o foco é voltado para a imagem da padroeira ornada com flores. 


\section{"JÁ TÁ CHEGANDO A FESTA DE NOSSA SENHORA DO CARMO": MEMÓRIAS E VIVÊNCIAS NA CIDADE DE BORDA DA MATA - MG}

\section{CLEYTON ANTÔNIO DA COSTA}

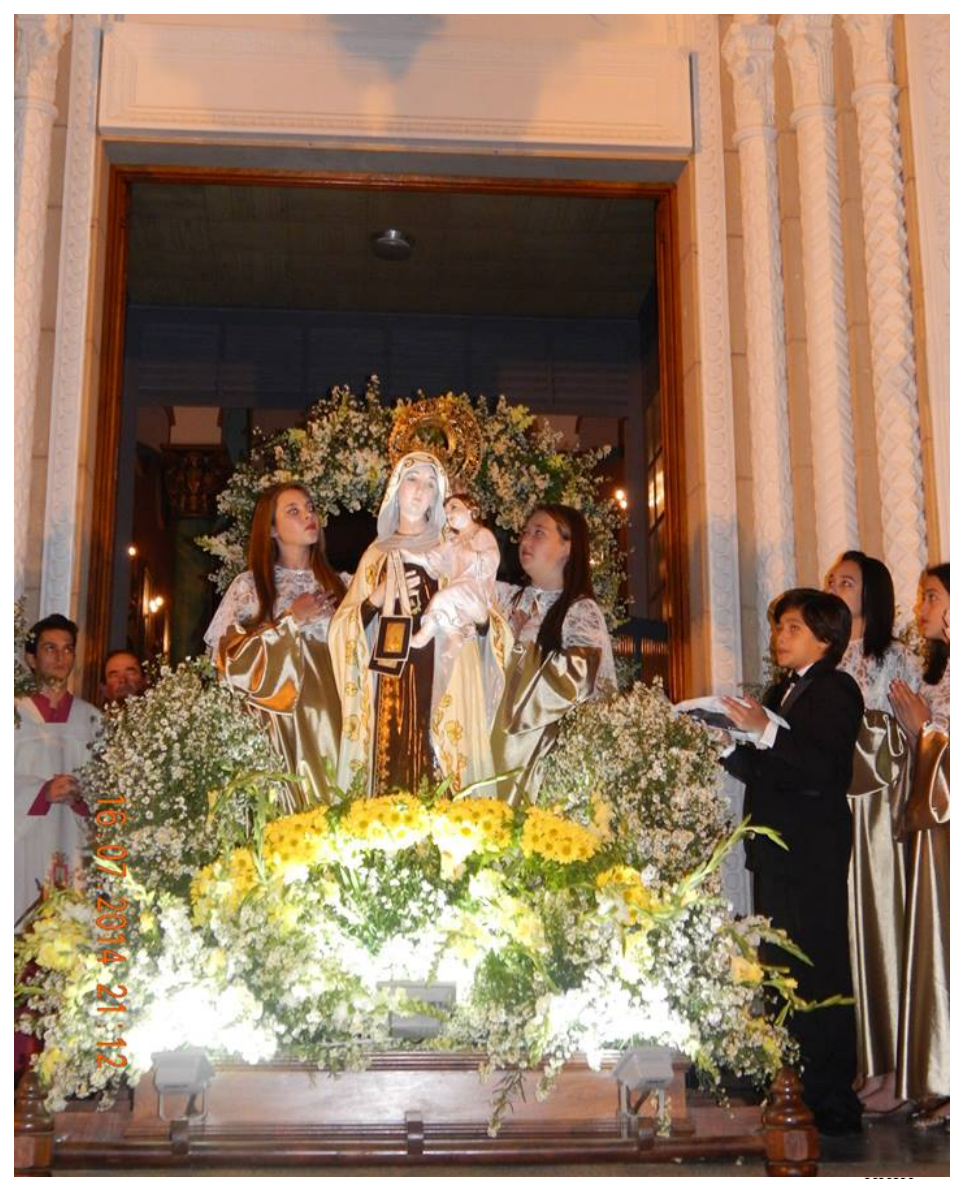

Imagem 5 - A coroação da padroeira, 16 de julho de $2014^{X X 1 X}$.

A coroação feita por adolescentes reforça a transmissão da devoção a Nossa Senhora. Em um contexto de oração, os jovens realizam a homenagem à padroeira na porta da Igreja Matriz, finalizando as práticas religiosas, e, encerrando mais um ano de festa.

\section{Algumas considerações}

As narrativas orais que percorrem esta pesquisa são frutos da gentileza em poder dialogar sobre alguns dos principais momentos da cidade de Borda da Mata. Diálogos que foram materializados pela atividade de, no presente, olhar o passado e significá-lo, construindo diferentes versões que permitiram focar a festa como uma marca nas lembranças e sentimentos dos nossos narradores.

Lembranças, sentimentos, reivindicações, lágrimas se misturaram à dinâmica do ir e vir da memória enquanto a festa era reconstruída oralmente. Foi um processo conduzido pelo ouvir. Um ouvir marcado pela sensibilidade de notar em alguns momentos o "nó na garganta" ao rememorar alguém que já foi e que gostava de estar no festejo.

A prática da História Oral foi o diferencial neste trabalho, a partilha de percepções e versões íntimas acerca do festejo aponta uma responsabilidade extrema ao pesquisador. Lidar com memórias é lidar com vidas. Juntamente com este corpus

Cadernos do Tempo Presente, São Cristóvão-SE, v. 08, n. 04, p. 93-105, jul./dez. 2017| http://www.seer.ufs.br/index.php/tempo 


\section{“JÁ TÁ CHEGANDO A FESTA DE NOSSA SENHORA DO CARMO": MEMÓRIAS E VIVÊNCIAS NA CIDADE DE BORDA DA MATA - MG}

\section{CLEYTON ANTÔNIO DA COSTA}

narrativo foram entrecruzados outros registros históricos ocasionando, desta maneira, um panorama diverso e fomentador de várias versões.

Assim, foi possível abrir um leque de questões que trilharam este trabalho, contemplando a festa como mecanismo pedagógico e arrecadador de renda por parte da Igreja Católica, que focou suas forças na construção de um novo templo. Mas, também, vimos o evento como forma de diversão, lazer de uma cidade que, durante o ano aguarda a efetiva chegada do período festivo, quando são realizadas práticas culturais que mostram os valores e interesses da população bordamatense.

\section{Notas}

\footnotetext{
${ }^{\text {I }}$ Doutorando no Programa de Pós-Graduação em Ciências da Linguagem pela Universidade do Vale do Sapucaí. Mestre em História Social pela Pontifícia Universidade Católica de São Paulo. Docente do Curso de História da Universidade do Vale do Sapucaí.

II Disponível em http://www.ibge.gov.br/cidadesat/topwindow.htm? 1. Acesso em 26 de janeiro de 2014.

III Prefeitura Municipal de Borda da Mata. Borda da mata comemora 87 anos. Jornal Guia de compras. MG, Julho de 2011. p. 2.

IV GUIMARÃES, José. Borda da Mata: Notas para a sua história. Pouso Alegre: Tipografia da Escola Profissional, 1958.

V ABREU, Martha. O império do Divino: festas religiosas e cultura popular no Rio de Janeiro, 18301900. Rio de Janeiro: Nova Fronteira; São Paulo: Fapesp, 1999, p.38.

${ }^{V I}$ Entrevista com a senhora Regina Maria Moreira. Em Borda da Mata, 02 de novembro de 2013.

VII Acervo pessoal.

VIII Entrevista com a senhora Lola Rodrigues. Em Borda da Mata, 24 de agosto de 2014.

IX Jornal Tribuna Popular, Ano II, nº18, 15/08/1998, p. 05.

${ }^{\mathrm{X}}$ Entrevista com o padre Luis Carlos Osti. Em Borda da Mata, 15 de janeiro de 2014.

${ }^{\mathrm{XI}}$ Fotografia pertencente ao acervo pessoal de Maristela Matos.

XII LUCENA, Célia Regina.. A festa (re)visitada: (re)significações e sociabilidades. In: LUCENA, Célia Regina; CAMPOS, Maria Christina de Souza. (Org.). Questões ambientais e sociabilidades. São Paulo: Humanitas, 2008, p. 99.

XIII ORIOLO, Edson. Festa da Padroeira. Jornal Folha Paroquial, Ano III, nº 06, Junho de 1999, p. 01.

XIV PEREZ, Léa Freitas. Festa para além da festa. In: PEREZ, Léa Freitas (et al). Festa como perspectiva e em perspectiva. Rio de Janeiro: Garamond, 2012, p. 27.

${ }^{X V}$ Entrevista com a senhora Maria Ângela Costa de Oliveira. Em Borda da Mata, 29 de março de 2011.

${ }^{\mathrm{XVI}}$ BURKE, Peter. Cultura Popular na Idade Moderna: Europa 1500-1800. São Paulo: Companhia das Letras, 2010, p. 244.

XVII CHARTIER, Roger. A História Cultural: entre práticas e representações. Lisboa: Difel, 199, p. 17.

XVIII Entrevista com o Senhor Carlos Rafael de Freitas, Em Borda da Mata, 10 de março de 2012.

XIX DEL PRIORE, Mary. Festas e utopias no Brasil Colonial. São Paulo: Brasiliense, 2000, p. 23.

XX Entrevista com o padre Luis Carlos Osti. Em Borda da Mata, 15 de janeiro de 2014.

${ }^{X X}$ GRANET-ABISSET, Anne Marie. O historiador e a fotografia. Revista Projeto História, $\mathrm{n}^{\mathrm{o}} 25$, São Paulo: EDUC, 2002, pp. 16 - 17.

XXII Fotografia gentilmente cedida por Austerlina Cobra.

XXIII Fotografia gentilmente cedida por Maristela Matos.

XXIV Entrevista com a senhora Austerlina Cobra Dantas Moraes. Em Borda da Mata, 21 de setembro de 2011.

XXV Entrevista com a senhora Lola Rodrigues. Em Borda da Mata, 24 de agosto de 2014.

XXVI PERROT, Michelle. A força da memória e das pesquisas históricas. Revista Projeto História, $\mathrm{n}^{\circ} 17$, São Paulo: EDUC, 1998, p. 359.

XXVII Jornal Tribuna Popular, ano VI, nº 65, 30 de julho de 2002, p. 05.
} 
“JÁ TÁ CHEGANDO A FESTA DE NOSSA SENHORA DO CARMO": MEMÓRIAS E

VIVÊNCIAS NA CIDADE DE BORDA DA MATA - MG

CLEYTON ANTÔNIO DA COSTA

XXVIII Entrevista com a senhora Maria Ângela Costa de Oliveira. Em Borda da Mata, 29 de março de 2011.

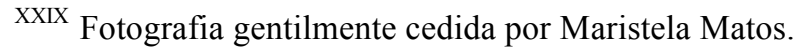

\section{Referências Bibliográficas}

ABREU, Martha. O império do Divino: festas religiosas e cultura popular no Rio de Janeiro, 1830-1900. Rio de Janeiro: Nova Fronteira; São Paulo: Fapesp, 1999.

BURKE, Peter. Cultura Popular na Idade Moderna: Europa 1500-1800. São Paulo: Companhia das Letras, 2010.

CHARTIER, Roger. A História Cultural: entre práticas e representações. Lisboa: Difel, 1990.

DEL PRIORE, Mary. Festas e utopias no Brasil Colonial. São Paulo: Brasiliense, 2000.

GRANET-ABISSET, Anne Marie. O historiador e a fotografia. Revista Projeto História, ${ }^{\circ}$ 25, São Paulo: EDUC, 2002.

GUIMARÃES, José. Borda da Mata: Notas para a sua história. Pouso Alegre: Tipografia da Escola Profissional, 1958.

LUCENA, Célia Regina.. A festa (re)visitada: (re)significações e sociabilidades. In: LUCENA, Célia Regina; CAMPOS, Maria Christina de Souza. (Org.). Questões ambientais e sociabilidades. São Paulo: Humanitas, 2008.

PEREZ, Léa Freitas. Festa para além da festa. In: PEREZ, Léa Freitas (et al). Festa como perspectiva e em perspectiva. Rio de Janeiro: Garamond, 2012.

PERROT, Michelle. A força da memória e da pesquisas históricas. Revista Projeto História, nº 17, São Paulo: EDUC, 1998. 